\title{
Understanding and Modeling the Human Driver
}

\author{
CHARLES C. MACADAM ${ }^{1}$
}

\author{
SUMMARY
}

\begin{abstract}
This paper examines the role of the human driver as the primary control element within the traditional driver-vehicle system. Lateral and longitudinal control tasks such as path-following, obstacle avoidance, and headway control are examples of steering and braking activities performed by the human driver. Physical limitations as well as various attributes that make the human driver unique and help to characterize human control behavior are described. Example driver models containing such traits and that are commonly used to predict the performance of the combined driver-vehicle system in lateral and longitudinal control tasks are identified.
\end{abstract}

\section{INTRODUCTION}

It should first be noted that the general topics of (1) understanding human drivers and (2) modeling their behavior, are quite broad in scope, either taken alone or together. In order to bound this paper to a somewhat more manageable scale, the emphasis here is on the control aspect of the human driver and its subsequent conceptual or computerbased modeling. That is to say, many behavioral aspects of driving - less related to common control task activities such as path-following, obstacle avoidance, or headway control - are not being addressed. Such behavioral activities might include items like driver distraction, side-tasking, or driver impairments that are more in the realm of human factors interests. Rather, the focus here is on the steering or braking/ acceleration control behavior of human drivers commonly observed to be present for both lateral and longitudinal control of the vehicle.

The principal roots of driver modeling as it relates to these control activities extend back to the early years of human-machine and aircraft pilot studies [1-14]. Those studies helped to reveal various properties unique to, or characteristic of, the human as a controller of dynamical plants [1, 4, 8, 14, 15] and certain vehicles [6, 16-20]. For example, in 1961 Ornstein [8] proposed the following transfer function, H(s), model of the human operator for pursuit-type manual tracking tasks,

$$
H(s)=\left(a_{1} \cdot s+a_{0}\right) \cdot e^{-s \tau} /\left(b_{2} \cdot s^{2}+b_{1} \cdot s+b_{0}\right)
$$

\footnotetext{
${ }^{1}$ Address correspondence to: C.C. MacAdam, The University of Michigan, Transportation Research Institute, 2901 Baxter Road, Ann Arbor, MI 48109 USA. Tel.: (734) 936 1062; E-mail: cmacadam@ umich.edu
} 
and noted that the numerator coefficient $\mathrm{a}_{1}$ associated with the velocity component, or anticipatory behavior of the human operator, was adaptive to changing plant dynamics and methods of visual presentation. In effect, this was an early observation of the adaptive nature of a human when interacting with different or changing plant dynamics and the use of prediction by the human operator. The parameter $\tau$ was an effective transport time delay.

More specific studies aimed at understanding the human as an automobile driver $[16,19-31]$ followed from or paralleled this type of manual control work. One example is a series of publications by Rashevsky in the late 1950s and early 1960s that addressed the topic of "Mathematical Biology of Automobile Driving" [25] wherein the basic model of the driver as a steering controller was treated in a purely geometric/ kinematic manner. The proposed algorithm for steering an automobile of designated width and length along a straight road of specified width amounted to issuing instantaneous steering corrections to the vehicle whenever it approached to within a specified margin of either lane edge. Although no vehicle dynamics were considered within this mathematical treatment, driver anticipation and driver delay properties were included as key parameters. Rashevsky interestingly observes in one work [32],

To sum up, we see that the combination of human parameters and of mechanical parameters enter into the process of driving in a manner which does not permit their clear-cut separation. The car and the driver form, in a sense, an individuum.

And in another work [33],

The car and driver constitute a complex feedback system. The behavior of the car results in certain reactions by the driver. Inversely, the behavior of the driver affects the behavior of the car. This 'man-machine' system cannot, in many instances, be separated into the purely 'mechanical' and the purely 'human' components. The system must be treated as a whole.

So we see that the idea of treating the driver and vehicle together as a combined system was recognized as important by researchers, absent even dynamical considerations of the vehicle response.

More complete treatments of the driver modeling effort and associated measurements of driver-vehicle system responses were also emerging in this same time frame, particularly with the increased use of computers and driving simulators. Example works that studied driver control behavior and accounted for the dynamics of the vehicle include studies by Wierwille [19], McRuer [22], Weir [18, 29-31], Kondo [17], Yoshimoto [20] as well as many others [16, 26-28, 34-37]. Key findings from these studies and others that followed are discussed further in subsequent sections of the paper. Other survey papers related to the topic of driver control behavior and modeling are found as well in such works as Good [38], Reid [39], Guo [40], and Peng [41]. 
In many cases, motivation for understanding and modeling the driver may be primarily related to achieving improvements in vehicle design per se, insofar as an interactive, or cause and effect, relationship is recognized between the vehicle and the driver [28, 38, 42-51].

\section{CHARACTERISTICS OF THE HUMAN DRIVER}

This section of the paper describes various human characteristics, both in terms of physical limitations as well as certain attributes, that should be incorporated into any serious effort aimed at modeling the control behavior of the human driver. Various example works - both historical as well as current - document many of the pertinent aspects of human control [15, 52-60]. The first subsection primarily addresses physical limitations of human sensory and physiological abilities and related driving cue issues [61]. This is followed by discussion of various human attributes that include such items as compensatory control behavior exhibited by drivers during regulation tasks, driver preview utilization, and adaptation capabilities of drivers when confronted with altered vehicle dynamics and/or changing operating conditions.

\subsection{Physical Limitations}

\subsubsection{Human Time Delay and Threshold Limitations}

There are certain basic properties of humans that are routinely observed by experimentalists when studying human-machine interactions. Humans are not "linear" elements. They exhibit time delays in reacting to stimuli. Sensed information (visual stimuli, motion cues, etc.) must also exceed certain thresholds prior to being detected. Other general limitations are:

- required processing times for sensed information

- information transmission time

- cognitive requirements to anticipate or predict ahead

- perceptions of higher derivative (or rate) information

Pure time delays are seen to be more harmful to human-vehicle system performance than "exponential" or dynamic lags as associated with first or second order system characteristics $[13,62]$. Laboratory experiments involving tracking tasks show that time delays greater than $40 \mathrm{~ms}$ produce degradations in performance for zero-order systems (i.e., simple positional control tasks) [13]. The detrimental influence of pure time delays on system stability was also demonstrated [9].

Simple reaction-time experiments (the time from stimulus to response with anticipation) show that visual response times under near ideal conditions are about $180 \mathrm{~ms}$. Comparable auditory and tactile response times are about $140 \mathrm{~ms}[59,60,63]$. 
It was also demonstrated that auditory delays increase to $300-400 \mathrm{~ms}$ as sound amplitudes approach the threshold detection levels [60]. Others have observed that the duration of the stimulus plays a role in reaction-times [64]. Consequently, reactiontime characteristics can display nonlinear properties insofar as they depend upon the amplitude as well as the duration of sensed information.

Some example threshold values for humans are listed below for several sensory channels (assuming long latency detection times in some cases) [52, 53]. Many of these threshold values depend upon exposure time, location, etcetera, and can be considerably more complicated than indicated by these example values:

$0.005 \mathrm{~g}$ linear accelerations

$0.1 \mathrm{deg} / \mathrm{s} / \mathrm{s}$ rotational accelerations

$5 \mathrm{mg}$ (von Fry hair method)

$355 \mathrm{mg}$ (von Fry hair method)

$0.0002 \mathrm{dynes} / \mathrm{cm} / \mathrm{cm}$

(0.63 dynes $/ \mathrm{cm} / \mathrm{cm}$ is ordinary conversation) vestibular saccule

vestibular semicircular canals

tactile - female face

tactile - male large toe

auditory

\subsubsection{Visual Characteristics}

It is known that velocity and position information can be extracted separately from a scene by the human vision system [65]. The jump-like saccadic response of the eyeball is primarily triggered by positional errors; the smoother pursuit mode of the eyeball is activated for constant velocity tracking of objects. However, the two modes work together yet independently of one another $[52,53]$. There is evidence that cells within the human visual system are directly responsive to velocity [66-69].

The perception of velocity is known to impose costs of increased time delays in the range of 30-200 $\mathrm{ms}[5,70,71]$. Limited abilities to perceive acceleration via the visual channel are observed except in cases where velocity-differencing operations occur by humans for slowly moving targets [52, 72].

Velocity information presented to humans in displays as "positions" (e.g., a speedometer gauge) show improvement in performance for tracking tasks, over cases in which velocity information is presented as a "velocity display" (e.g., nulling of a rotating disk display) [73]. Velocity information obtained from the peripheral visual areas is generally found to be valuable, particularly as redundant information to positional information obtained from the central foveal vision areas [74-76]. It is also observed that basic peripheral velocity information should be compatible with the expectations of humans [76].

The ability of humans to look ahead and preview information helps to reduce some of the time delay limitations indicated above [77]. In other cases where preview may not be available, such as driving and responding to wind gusts, higher order predictive 
requirements of humans come into play in order to self-generate rate information for vehicle control purposes.

\subsubsection{Motion Influences}

Much of the higher derivative information used by humans for control purposes is obtained from the vestibular (inner ear) and kinesthetic (body distributed) channels. Simulator studies show that the presence of accurate motion information to supplement visual information generally leads to superior flying and driving performance over comparable conditions when no motion is present [3, 6, 73, 78-84].

Studies such as $[6,85]$ show that motion effects help to reduce uncertainties in observed responses and provide for enhanced prediction and gain compensation by the human controller. The importance of accurate and reliable vestibular cue information is noted in simulator studies such as [6]. Cue fidelity issues have also been noted with regard to pilot training and successful transfer to flight conditions. Experience or skill level may also play a role as to cue preferences during simple driving tasks as suggested in [86].

\subsubsection{Auditory Information}

The use of auditory information is generally seen to be most beneficial when acting as a supplementary cue within a multi-channel environment [87, 88]. For tracking control tasks, it is noted in some studies that human time delay characteristics were as short for auditory as for visual channels [88].

Generally, the use of auditory information as redundant and reinforcing information is seen as helpful for improving system performance. Auditory information, though, is most useful under high workload conditions as redundant information supplementing the visual channel [53].

\subsubsection{Tactile and Haptic Information}

Tactile and haptic cue information is normally conveyed to the driver through the steering wheel and throttle/accelerator pedals. A certain portion of information is also available through such channels by sensing small skin surface vibrations or circulating wind, etc. Steering wheel torque information can be particularly useful to drivers for detecting sudden changes in tire/road friction as well as anticipating control responses for roadway disturbances and wind gusts. Example ideas being advanced in this area are the so called haptic steering wheel device [89] and certain electric steering systems [90].

\subsubsection{Ranking of Sensory Cue Influences for Human Drivers}

General review of the overall literature leads to a clear impression that visual aspects of driving are of the highest significance. Quotes referring to the driving process as depending upon $90 \%$ of visual information are not uncommon [91-93]. There is also 
a certain common sense aspect to this reasoning process given our own personal experiences and observations, the emphasis that government agencies normally place upon visual acuity tests in registering drivers, and the absence of drivers with severe visual impairments operating motor vehicles. Laboratory simulator studies (and many video games) also demonstrate that most humans can adequately control and navigate vehicles using only vision, even with distorted or inaccurate visual feedback information in many cases.

So, it is simply observed that vision is very important and the exact level of importance can likely vary depending upon the specific driving scenario and task conditions. For example, during straight-line driving in crosswind conditions, drivers are likely to increase their dependence upon yaw motion and lateral accelerations due to wind disturbances [42, 46]. This would tend to activate and increase driver utilization of vestibular rotary motion information, vestibular lateral acceleration cues, and kinesthetic "seat-of-the-pants" (somatosensory) feedback sensations. The percentage of visual cue information, relative to the total cue information, would be reduced under these circumstances due to the increased usage of vestibular and kinesthetic channels. However, the visual channel still remains dominant. Other driving scenarios, such as heavy fog conditions that severely limit driver vision, also provide common evidence of our dependency upon vision for routine driving.

The process of ranking sensory information becomes somewhat less obvious after vision is removed from the list. However, motion cues related to higher derivative information (linear and rotational accelerations as well as rotational velocities) normally sensed by the vestibular and kinesthetic channels tend to show up frequently as topics of importance for most simulator or motion-based studies [35, 82]. It is difficult in many cases to identify the separate influences and associated importance of these two sensory channels since most acceleration information is generally detected simultaneously in different ways by both senses. Even under conditions of significant rotation where the vestibular channel could seem to have certain advantages, some form of rotational motion might still be detected by kinesthetic mechanisms that drivers use to locate themselves within a vehicle compartment. Lumping these two sensory capabilities together at a second level of importance seems reasonable given their tendency to provide cooperative and reinforcing information on accelerations. It might further be observed that although the vestibular channel provides additional information such as rotational rates of change and the sense of gravitational orientation, the kinesthetic sense has certain advantages by being distributed throughout the body and also provides some velocity sensing information via body vibrations and limb movements, as well as control force/torque sensations from the steering wheel and control pedals. Again, as in the case of vision considerations, selected driving scenarios can probably be identified in which drivers depend more on vestibular-sensed information than kinesthetic, and vice versa. 
The tactile and auditory channels remain. The tactile sense often is engaged with the kinesthetic sense (haptic) for various task activities during the driving process. Interaction with the steering wheel and foot pedals are good examples. Wind currents passing over the face and hands can also provide additional information on movement and vehicle speed. To the extent that the tactile sense is also distributed across the body and has frequent cooperative interaction with the kinesthetic sensing mechanisms, it would take on a more likely level of importance in the driving process than the auditory channel.

A top to bottom ranking of the primary sensory channels used in driving would then be:

1. Vision;

2. Vestibular and Kinesthetic;

3. Tactile;

4. Auditory.

The ranking of specific cues associated with these sensory channels would organize themselves accordingly into several corresponding groups. For example:

- translational/rotary position and velocity information from the visual channel followed by,

- translational/rotary velocity and acceleration information sensed by the vestibular

- linear acceleration, force/torque information from the kinesthetic body senses

- acceleration information derived from visual velocity differencing mechanisms followed by,

- small amplitude vibratory information sensed by tactile senses

- auditory information regarding velocity, movement, and accelerations

Note that most of the secondary cues also provide redundant/reinforcing cue information during the driving process. This can help drivers to more quickly confirm decisions and better estimate information obtained from the more primary channels. Estimating speed, for example, is often enhanced by the inclusion of auditory information [35]. So, even though visual cues would be relied upon primarily, additional auditory information and kinesthetic/tactile vibratory information will generally improve the speed estimation process by the driver.

\subsubsection{Manual Control Considerations}

Basic observations regarding adaptation and gain compensation by human subjects, as well as preferred optimum gain settings, are reported in [3, 5, 27]. It is known that as the complexity of the controlled system increases (often referred to or expressed by the term "control order"), the difficulty increases for the human controller. Poulton [94] observes that zero-order plants (position control) require one correction by the 
human; first order systems require two control corrections, etcetera. RMS system errors increase from about $40 \%$ to $100 \%$ as the order of the controlled system increases from first order to second order (i.e., from human control of velocity to control of acceleration).

As task difficulty increases due to system complexity, system performance is decreased, time delays increase, gains are lowered, control remnant is greater, higher estimates of workload by subjects are noted, and greater interference within other tasks is observed [53]. The associated requirements by the human operator to preserve stability under such conditions results in the need to generate longer lead times which are frequently associated with increased workload [6, 95]. Perceptually, the need to obtain higher derivative information needed for adequate control burdens the human operator under such circumstances $[53,95]$. It is also noted that increased usage of bang-bang control strategies by human operators is employed as the order of the controlled system increases [96-98].

Figure 1 illustrates a subset of simple control system elements that describe some of the aforementioned physical characteristics of the human driver. These elements
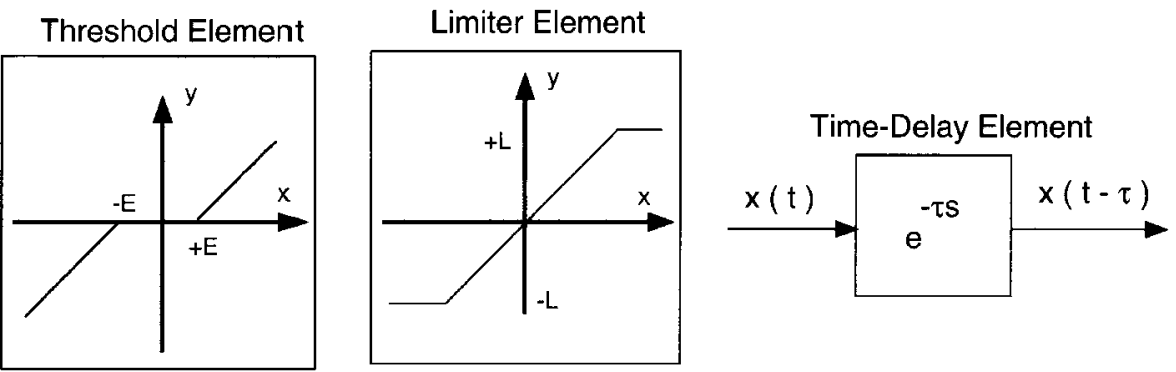

Frequency Response Element
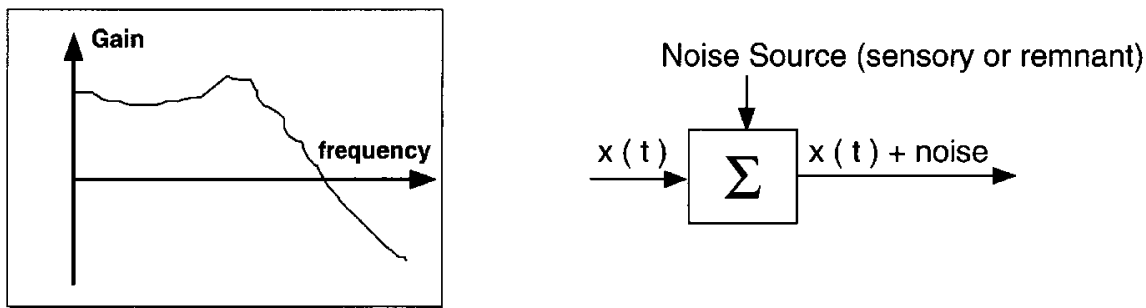

Fig. 1. Example elements used to describe basic limitations and characteristics of the human sensory and neuromuscular system. 
include such items as (1) a transport time delay property, (2) various forms of dynamic response characteristics that can be used to represent neuromuscular dynamics for steering/braking/acceleration output control responses, or, dynamic properties of various input sensory organs, (3) threshold properties of human sensing, (4) rate-limiting properties of sensed angular rotations, (5) signal noise associated with sensory inputs or self-generated remnant noise in output responses, and (6) visual acuity capabilities and associated properties of the human visual system. In large part, these represent a group of fundamental physical limitations for the human driver.

\subsection{Physical Attributes}

In contrast to the above section, various human characteristics that might best be classified as attributes are described here. These include such items as preview utilization, adaptation to changing dynamic characteristics of the controlled vehicle, learning, anticipation, and planning abilities. Clearly, some of these are more difficult than others to model, but should still be recognized as part of what it means to be a human driver.

\subsubsection{Preview Utilization}

The human driver must look ahead - a simple statement and observation, but one that was surprisingly ignored in many early driver models. Sheridan $[99,100]$ early on was one of several who emphasized and recognized preview as a key property of human drivers, or, as "creatures who look ahead." Kondo and Ajimine's work [17] focused on measuring the driver "sight-point" ahead of the vehicle and developed a steering model based on deviations between the sight point and the desired course. Yoshimoto $[20,101]$ also included preview as part of a steering algorithm and more recently with Katoh and Inoue [102] for representing driver anticipation of speed adjustments when entering a curve. Examples of other works that also include preview as a key ingredient in human manual control applications as well as driver models include Kleinmann et al. [103-105], Tomizuka [106], MacAdam [107, 108], Levison [70, 109-111], and Reid [77].

The use of preview allows the human driver to not only provide anticipatory control responses for upcoming or developing driving scenarios, but to also conduct certain planning activities in response to developing situations. Preview allows the driver to directly observe the time-advanced path input requirement (or braking/ acceleration goal) and to then project into the future a predicted vehicle response based upon the estimated control response needed to achieve a certain goal (path error minimization, desired stopping point, etc.) In short, preview is an essential part of human driver control behavior. 


\subsubsection{Adaptive Control Behavior}

Another key attribute that defines the human driver is the ability to adapt to not only different controlled vehicle dynamic plants but to altered operating conditions as well. This "robustness" feature was recognized in many early laboratory and pilot studies $[2,4-7,10,11,13,14,18,22,71,112]$, as well as various vehicle-based studies [22, 31, 112, 113]. Many of the manual control studies included examples of first, second, and third-order controlled plant dynamics during tracking tasks in which either the plant gain or the polarity of the plant dynamics were suddenly altered. Generally, the human subject was able to adapt rather quickly (usually within one or two seconds) to most of these abrupt changes, following a very brief transient period during which tracking errors would increase. These errors then subsided upon adaptation by the human subject to the new plant dynamics.

Similar observations regarding human operator adaptive control behavior, but specifically related to the task of straight-line automobile regulation were offered by McRuer et al. [23, 37, 112] in the now well known cross-over model experiments for automobile drivers (and aircraft pilots previously [6]). This experimental observation is summarized by the well-known describing function,

$$
H(s) \cdot G(s)=\omega_{c} \cdot e^{-s \tau} / s
$$

that represents the combined driver, $\mathrm{H}(\mathrm{s})$, and vehicle, $\mathrm{G}(\mathrm{s})$, quasi-linear transfer function in the immediate vicinity of the crossover frequency, $\omega_{\mathrm{c}}$, during regulatory tracking tasks in the presence of small random-like system disturbances. The transport time delay parameter $\tau$ is the effective system latency in this representation. The above expression essentially encapsulates the notion of dynamic invariance under such conditions and is an alternate way of stating driver adaptation to changing plant dynamics. Furthermore, it provides a critical anchor point for helping to authenticate the control behavior of any candidate driver model intending to mimic human drivers at least for linear-regime regulation control tasks.

As it turns out, the broader picture is somewhat more complex than this $[108,114$, 115]. While experiments show that the linear regime describing function of actual driver-vehicle systems [113] exhibits cross-over model behavior, it does so only in the immediate vicinity of the crossover frequency. In fact, at lower frequencies where much of our driving actually occurs [21], driver-vehicle measurements [113] show a significant increase in slope gain that transition towards $-60 \mathrm{db} /$ decade and a corresponding phase shift of -270 degrees at DC (versus the comparable cross-over model values of $-20 \mathrm{db} /$ decade and -90 degrees of phase shift). This is an important distinction, since the temptation to model human-vehicle control behavior is frequently based on the cross-over model characteristic alone and consequently such models suffer significant errors at lower frequencies where the vast majority of driving occurs. Instead, driver modeling efforts should recognize the experimental observations of driver-vehicle systems at both low and mid-frequency ranges and 
validate accordingly, thereby exhibiting the increased gain and phase shifts at low frequencies and accompanying cross-over model behavior in the mid-frequency range. (A typical cross-over frequency for attentive automobile drivers in steering regulation tasks is about 4 radians/s.)

Within the nonlinear realm, similar observations have been noted regarding driver adaptive control behavior. For example, in a special set of test track experiments $[114,115]$ conducted with an over-steer vehicle operating above its critical velocity along a circular path, it was observed that drivers can stabilize and control such directionally unstable vehicle plants - primarily through use of slow, oscillatory, counter-steering behavior. Associated analyses using a driver model noted that the presence of a nonlinear internal vehicle model (within the driver model structure) was an important ingredient for reproducing that distinctive steering behavior - suggesting that drivers can identify and internalize even nonlinear controlled vehicle dynamics as part of their adaptive control behavior.

\subsubsection{Internal Vehicle Model Concept}

The notion or concept of human drivers possessing an "internal model," or inputoutput understanding of the vehicle being controlled, is also closely linked to the adaptive control and preview utilization traits noted above. The primary motivation is to represent the observed abilities of human drivers to estimate or to project the current vehicle state into the future. This allows the driver to compare the timeadvanced expectation of the vehicle state at some future time with the directly observed previewed input requirement (path to follow, desired headway, stopping point, etc.) This of course depends upon the driver having some basic understanding of the controlled vehicle dynamics - hence the internal vehicle model concept or its equivalent - in order to perform the projection. Neural network models [116-126] of the driving process essentially subsume many of these ideas within the neural net architecture and associated connection weights. Fuzzy logic [127] and genetic algorithm [128] approaches accomplish much the same. Regardless of the method, the intent is to recognize these basic traits and abilities of human drivers and to capture some elementary characterization of these abilities within the modeling approach.

\subsubsection{Miscellaneous Attributes}

Other miscellaneous and important attributes of the human driver include abilities to (1) select or plan alternate paths along curved roads or around obstacles (such as "corner-cutting" behavior) so as to provide greater margins of road adhesion for maneuvering [129], (2) learn and remember various scenario-linked control responses for common maneuvers [130], (3) alter control attention based on driving conditions, and (4) invent or create new control strategies based on developing or unfamiliar situations. 
In light of these attributes and the aforementioned physical limitations, the human driver still possesses, on balance, remarkable abilities and creative instincts for dealing with the myriad of possible driving situations, routine and emergency-like, that present themselves as part of the overall driver control process. Furthermore, the ability of drivers to sense and gather information about their driving environment often goes unrecognized as a key contributor to these remarkable control abilities. Those sensory and interpretation abilities help make the human driver particularly unique, and accordingly, especially challenging from a modeling perspective.

\section{MODELLING THE HUMAN DRIVER}

Of all the key properties and characteristics of the human driver cited above, a certain core group is deemed essential to provide a minimal representation of the human driver. This includes:

- provision for a transport time delay;

- use of preview by the driver for sensing upcoming lateral and longitudinal control requirements;

- driver adaptation provision so that alterations to the controlled vehicle dynamics and operating conditions can be approximated or accounted for within the driver model;

- exhibition of the aforementioned linear regime "crossover model" behavior in the immediate vicinity of the crossover frequency;

- presence of an internal vehicle model - or equivalent capability - within the structure of the driver model in order to help estimate future controlled vehicle responses.

A secondary set of additional and desirable features, though not necessarily essential, depending upon the application, include such items as:

- provisions for processing incoming sensory signals to account for neural delays, thresholding, rate limiting, and dynamical properties of individual sensory channels;

- neuromuscular filtering elements for output channels such as steering, braking, and throttle control responses;

- previewed path adjustment capabilities/strategies by the driver model to account for driver skill-related abilities or preferences in selecting alternate or modified paths;

- driver abilities to adjust speed based on upcoming lateral path requirements in order to facilitate path tracking along curves and around obstacles, thereby enhancing directional stability during such conditions; 
- provisions for surprise or situational awareness features within the model that allow discrimination between control responses provided by well rehearsed or highly practiced driving scenarios versus unrehearsed or less familiar driving scenarios;

- inclusion of some form of driver skill factors, or corresponding parameter adjustments, that are known or estimated to correlate with different categories of driver experience or skill.

Numerous driver modeling efforts exist in the literature and many contain various features noted above. Certain models that are primarily focused on an optimal characterization of driver control performance such as formula-1 driving [131, 132], or related types of automated or more idealized driver performance [51, 133-136] are duly noted as providing a type of benchmark performance that reflects highly practiced and skilled sets of driver control behaviors. However, the emphasis here is more on the types of models that can represent or mimic a broad range of driver control behavior, and therefore include provisions for many of the cited limitations and attributes of human drivers. A sampling of parametric driver models that incorporate some of these features include the works of [16-20, 39, 40, 44, 48, 50, 51, 71, 108, 110, 137-146].

Other examples of driver modeling efforts that have incorporated artificial intelligence methods such as neural networks, fuzzy logic, and genetic algorithms include the works of $[117-127,147-149]$. These latter modeling approaches essentially capture many of the key driver properties and characteristics noted above as part of their tuning methodology which typically involves network training, or iterative-like parameter adjustments, in order to match a desired or targeted driver control behavior. However, lack of parameters directly linked to physical characteristics of the driver often make these models and associated results more difficult to interpret.

\subsection{Longitudinal Control}

Examination of the technical literature related to the longitudinal control behavior of drivers reveals that models and associated studies of driver braking/acceleration control behavior are relatively sparse when compared to the comparable body of works related to the lateral steering control topic. Example studies that have addressed the braking behavior of drivers and/or models of driver longitudinal control during braking or acceleration include the works of $[3,27,36,102,115$, 126, 139, 144, 149-155]. Newcomb and McLean [36, 144] provide examples of fairly detailed modeling of the various components of the driver-vehicle system during longitudinal braking. Rompe's work [154, 155] in addition to Newcomb and McLean also provides a useful source of measurements of representative driver control behavior during hard braking. Recent measurements by Fambro 
et al. [156] also include braking performance results for a variety of drivers operating passenger cars and light trucks. The work of Fancher and Bareket [139] is primarily concerned with the headway control behavior of typical drivers and their interaction with ACC systems during highway driving. Peng's recent work [41] using a modified version of the Gipp's model [157] is likewise advancing the modeling effort in the headway control area and appears to accurately represent both macroscopic as well as microscopic traffic flow behavior of human drivers.

Newcomb and Mclean show examples of measured and predicted driver longitudinal control behavior during controlled stops. When the driver longitudinal data is normalized on a time-to-go (stopping time) basis, a fairly consistent pattern of longitudinal deceleration is indicated and their model was able to represent corresponding behaviors for passenger car and commercial vehicle tests. The normalized deceleration pattern reported by Newcomb and Mclean is also observed in similar measurements and model predictions by others [151, 154]. An example application of a simple optimal preview control model, using a variable (time-to-go) preview time, was also shown to predict longitudinal driver behavior very similar to that reported by Newcomb and McLean when applied to controlled stops of a light truck [115].

A technical item of current interest in driver longitudinal control behavior is the issue of "looming" [52, 55, 139], or how objects ahead of drivers are perceived to be moving depth-wise, and thereby, how they represent themselves as smaller or larger retinal images within the driver's eye. (Newcomb and McLean also discussed this as part of their earlier model, though different terminology was used.) Closely related to the looming issue (changing size of the retinal image) is the accompanying binocular "disparity" phenomena [52] in the eye that causes the image to move laterally on the retina as well (objects moving toward the observer move outward on the retina, and vice versa). Consequently, drivers normally have two basic pathways in the neuralvisual system that provide sensory information on the relative fore-aft motions of vehicles or objects ahead of them. Further understanding of these and other visual phenomena may provide future means for developing improved models of driver longitudinal control behavior.

It is also worth noting that longitudinal regulation-like control experiments with actual vehicles, similar to McRuer or Weir's cross-over experiments, do not appear to have been conducted to replicate similar driver-vehicle response characteristics for the longitudinal control problem. Nevertheless, most of the models of driver longitudinal control behavior cited above do contain driver transport delay properties, driver preview, and some form of internal vehicle model that permits projection of future vehicle longitudinal responses. It is assumed that similar driver-vehicle traits still apply to the longitudinal control problem, even though experimental studies that could address many of these issues are lacking. 


\subsection{Lateral Control/Combined Control}

Examples of more recent driver models that incorporate many of the elements noted at the opening of this section and that are also focused primarily on the lateral control or combined lateral/longitudinal control problem are documented in such works as $[48,110,111,145,146,151,157,158]$. Many of these works include provisions for braking, acceleration, and steering control by the driver, although most of these models emphasize the steering control component, using the speed-control element primarily to facilitate the lateral path control requirements. Levinson's recent work [111] for the U.S. DOT with the "Integrated Highway Safety Design Model" is one such example. Prokop's recent model [145], as well as Savkoor [146], also address many of these combined control issues and apply across a variety of linear and nonlinear maneuvering conditions.

Another example of this class of driver models, and especially familiar to the author, is the so-called GM/UMTRI driver model [159]. It was recently developed for General Motors by UMTRI as part of a research project aimed at developing a driver model capability applicable to nonlinear, near-limit operating conditions. This model is an extension of an earlier UMTRI driver model [108, 115] that has been used previously for linear or quasi-linear closed-loop steering applications. Features of the newer nonlinear model [159] are seen in the block diagram of Figure 2 and are shared with many of the models cited above. It will be used as the primary surrogate for this class of driver models in the following discussion.

The overall driver model depicted in Figure 2 interfaces with an arbitrary external vehicle dynamics program. Vehicle response signals (e.g., lateral and longitudinal position, roll angle, yaw rate, sideslip velocity, lateral acceleration, forward speed, and yaw angle) from the external vehicle model flow into the driver model through the Sensory Limitations and Noise block wherein sensory neural transport delays, filtering, rate limiting, noise addition, and various nonlinear signal conditioning effects can be applied to any incoming vehicle response signal. The output of this sensory block represents the input to the human driver cognitive portion of the model that, in turn, is responsible for generating the indicated steering and speed control commands.

The cognitive portion of the model is comprised of the group of elements represented by the blocks labeled as Internal Vehicle Dynamics, Prediction, Steering Control, and Speed Control. The Internal Vehicle Dynamics block creates a simplified nonlinear approximation of the external controlled vehicle. The Prediction block uses that simplified nonlinear vehicle representation to project an estimated vehicle response into the future.

The blocks on the right side of the diagram primarily associated with the Previewed Scene represent the driver's perception of the desired path input (observed as a previewed set of left and right lane edges or obstacles) ahead of the vehicle. The 


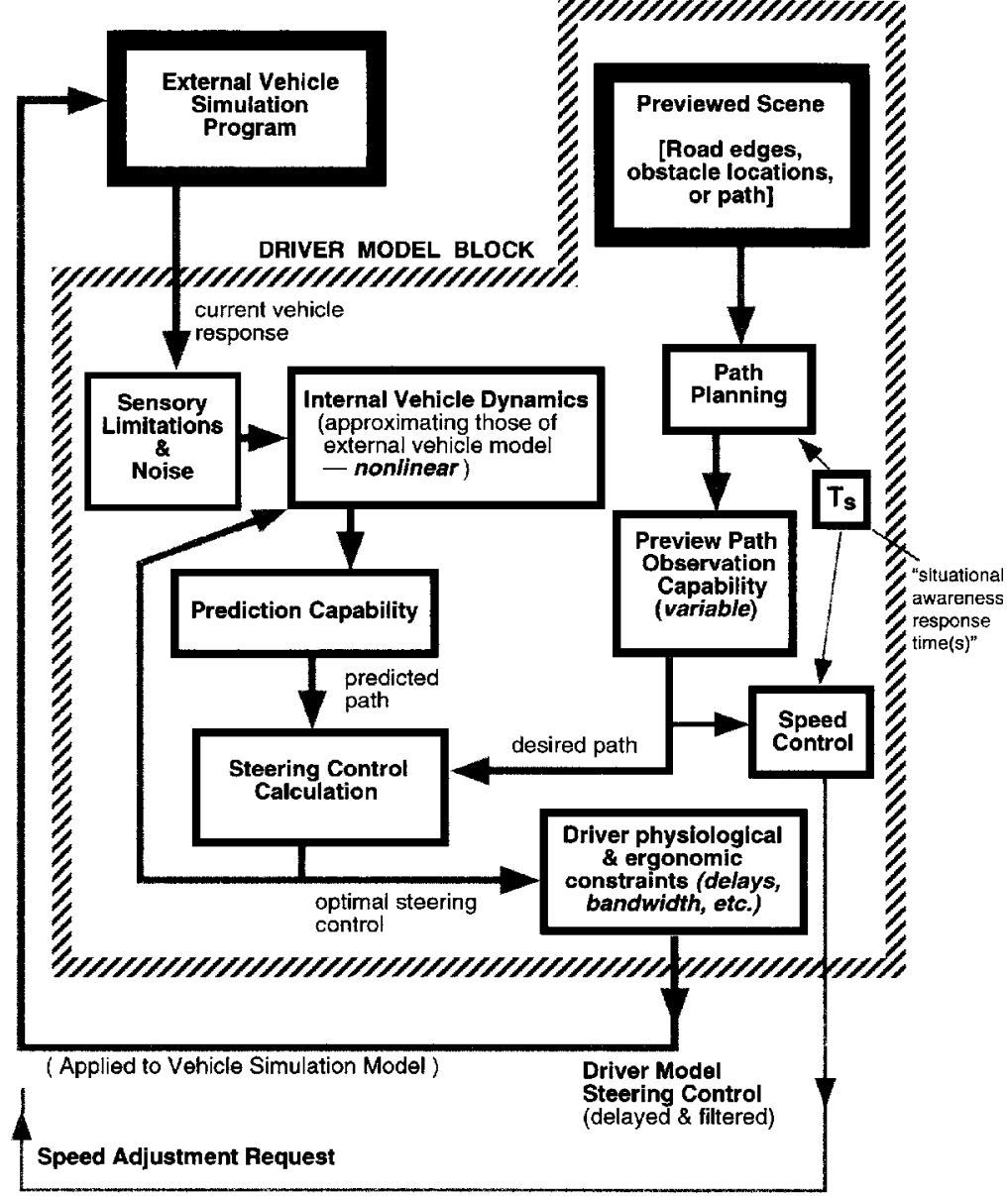

Fig. 2. GM/UMTRI nonlinear driver model [159].

Path Planning element allows various path smoothing or "corner-cutting" modifications to be performed by the driver on the raw scene information. The Preview Path Observation Capability block allows for on-the-fly adjustment of driver preview characteristics to enhance maneuverability and stability for changing roadway geometries. This adjustable or variable driver preview feature is important since driver preview is an obvious property over which drivers have direct control and which, in turn, is seen to very powerfully affect the performance of the closed-loop system under both linear as well as nonlinear operating conditions. 
The Steering Control Calculation block calculates a steering control response that minimizes an integral of path errors over the current preview time interval. (A variety of different control laws can of course be represented in this block depending upon the particular approach.) This "optimal" steering control response is then passed to the final output block labeled as Driver Physiological and Ergonomic Constraints wherein a designated transport delay is applied, along with optional neuromuscular filtering treatments, nonlinear rate and magnitude limiting, and output remnant noise. The resulting output from this block is then applied to the external (controlled) vehicle as the driver steering control response.

The other output from the driver model is a Speed Control request based on upcoming path requirements. Its primary purpose is to maintain a designated speed of travel, unless upcoming curves or obstacles produce lateral maneuvering requirements that would cause lateral acceleration demand to exceed specified thresholds. These designated thresholds would ordinarily be related to either comfort or limit stability considerations, depending upon the particular application. Upon exiting curves or obstacle encounters, speed control requests are likewise incremented accordingly to regain the designated travel speed. At present, the longitudinal control module is relatively simple, using estimated curvature from the preview module, current speed, and maximum desired lateral acceleration levels to estimate the required speed changes over the ensuing approach to the curve or obstacle (similar in concept to Yoshimoto [102], Levinson [111], Savkoor [146], or Hisaoka [151]). Despite the simplicity of the speed control feature, the potential for enhancing its capability is relatively straightforward, particularly in terms of developing a more natural acceleration-based control structure that directly parallels its more complete lateral control counterpart.

The remaining item in Figure 2 labeled as Situational Awareness Response Time is essentially an optional transport delay, $\mathrm{T}_{\mathrm{s}}$, that can be applied at the beginning of a curve or obstacle encounter so as to delay the start of the driver response. Once the driver model does respond, the designated delay is removed. Its purpose is to permit simulation of surprise-like encounters of varying degree, versus those with more highly practiced or anticipated responses. It can also be used to represent one of several characteristics possibly related to driver skill or experience.

As seen, the indicated model has a number of features that render it suitable to a broad category of potential applications, particularly for near-limit maneuvers beyond the reach of response predictions provided by conventional linear driver models.

\subsection{Example Application}

By way of example, Figure 3 depicts the simulation of a sudden tire failure (or "blowout") event during an obstacle avoidance maneuver (double lane change). The simulated failure occurs on a high friction surface for the left front tire at the $\mathrm{x}=89 \mathrm{~m}$ location and the ensuing response causes the vehicle to drift out of the lane prior to its 


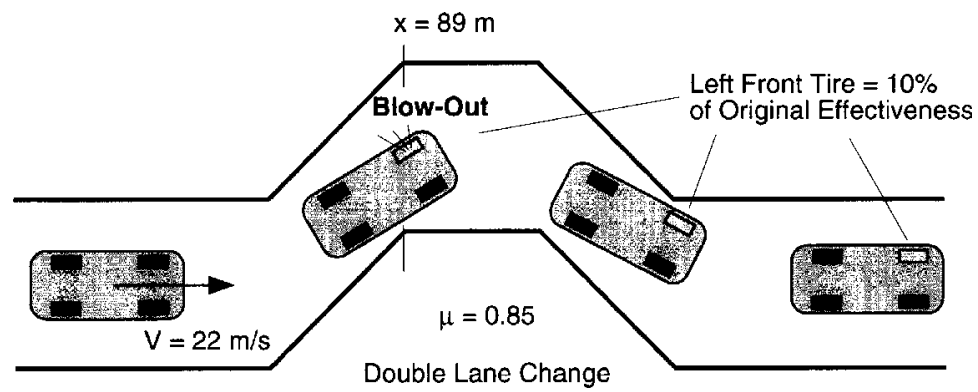

Fig. 3. Double lane change maneuver and tire failure example.

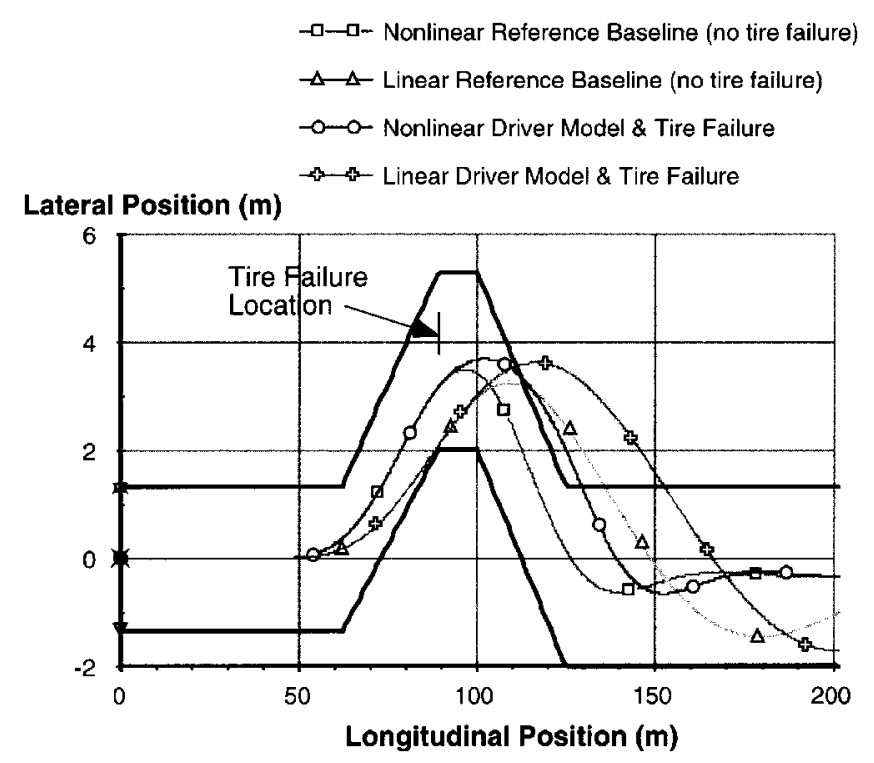

Fig. 4. Linear and nonlinear driver models - path trajectories with and without front tire failure.

eventual lane recovery as seen in Figure 4 (Nonlinear Driver Model \& Tire Failure case). The simulated tire failure assumes an abrupt loss of $90 \%$ tire force capability at the left front tire location. Also seen in Figure 4 are corresponding path responses for (a) the nonlinear driver model response absent a tire failure (Nonlinear Reference Baseline), (b) the equivalent linear driver model response absent a tire failure (Linear Reference Baseline), and (c) the equivalent linear driver model response with a tire failure (Linear Driver Model and Tire Failure). The corresponding driver steering and lateral acceleration responses are seen in Figures 5 and 6. (The equivalent linear driver 


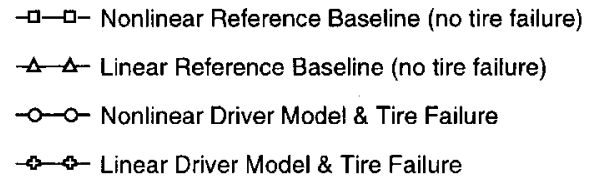

\section{Driver Model Steer Angle (deg)}

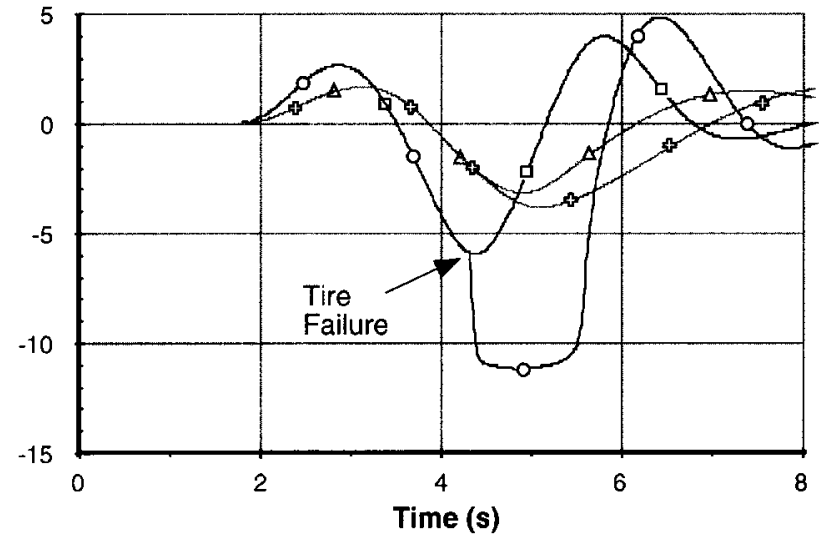

Fig. 5. Driver model steering responses - with and without front tire failure.

model representation is obtained here by replacing the internal model nonlinear tire and vehicle components with their linear-regime counterparts.)

As seen, the indicated maneuver normally produces a peak lateral acceleration of about $0.6 \mathrm{~g}$ 's when no tire failure occurs. With the tire failure present, the nonlinear driver model produces an immediate corrective steering reaction to the tire failure at about the 4.5-s time mark. However, because of the sudden loss of available tire force and the saturating tire force characteristic present under these operating conditions, the vehicle still drifts somewhat outward from the center of the intended travel lane but regains path control shortly thereafter. This adaptive sensing of the sudden change in controlled vehicle dynamics by the nonlinear driver model is important, as is its internal nonlinear "understanding" of the associated vehicle response under these circumstances. Both properties help to equip it with some of the important human-like adaptive qualities noted earlier.

When this response is compared to the linear driver model result, significant differences are noted. First, the linear model does not respond immediately to the tire failure event since it does not detect force-related or acceleration terms directly. Rather, it responds only after path errors have accumulated over time as a result of the loss of the front tire force. Also, because of the linear tire characteristics present within the linear driver model, the linear driver model always under-estimates the required steering, with or without a tire failure event, when operating under nonlinear 


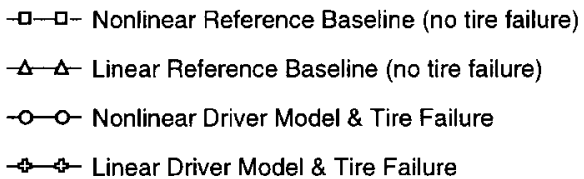

Lateral Acceleration (g)

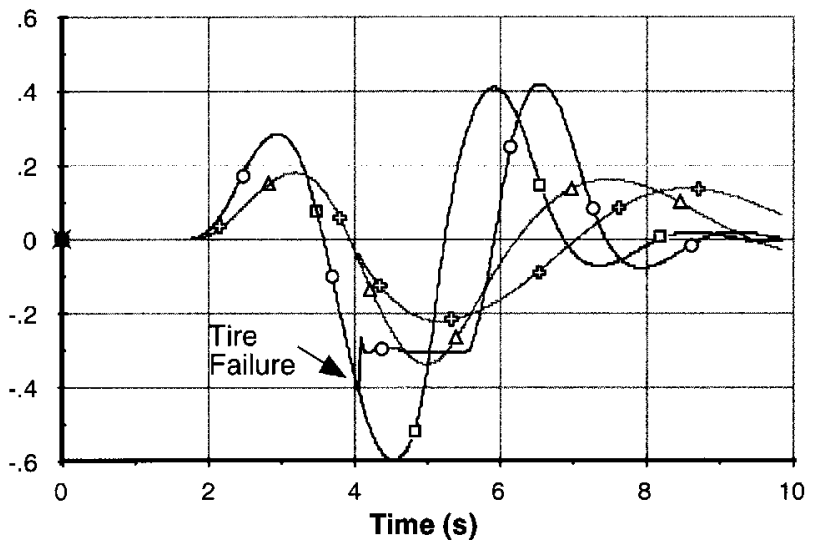

Fig. 6. Lateral acceleration responses with and without front tire failure.

conditions. This is also illustrated by simply comparing the linear and nonlinear baseline results alone (absent any tire failure) and noting the smaller and more sluggish steering responses for the linear driver model - a direct result of these different tire force characterizations. Thus, even for the case of a linear driver model that is also enabled to sense force or acceleration terms directly as part of its steering control behavior, it would still significantly under-estimate the corrective steering required due to its linear tire force and associated linear model assumptions.

The tire failure example illustrates the increased sensitivity of a nonlinear driver model to external vehicle conditions during which the dynamics of the controlled vehicle become suddenly altered and operate for significant periods of time under nonlinear conditions. Under these circumstances, the vehicle dynamics present in the internal nonlinear driver model (or an equivalent predictive capability) help provide significantly more responsive and beneficial steering behavior. Such behavior is also more akin to the type of adaptive human control responses cited earlier.

\subsection{Nonlinear Operating Conditions: Simulator Experiments Versus Model Predictions}

To examine the extent to which the same nonlinear driver model characterization can represent driver steering behavior of actual drivers operating under nonlinear 

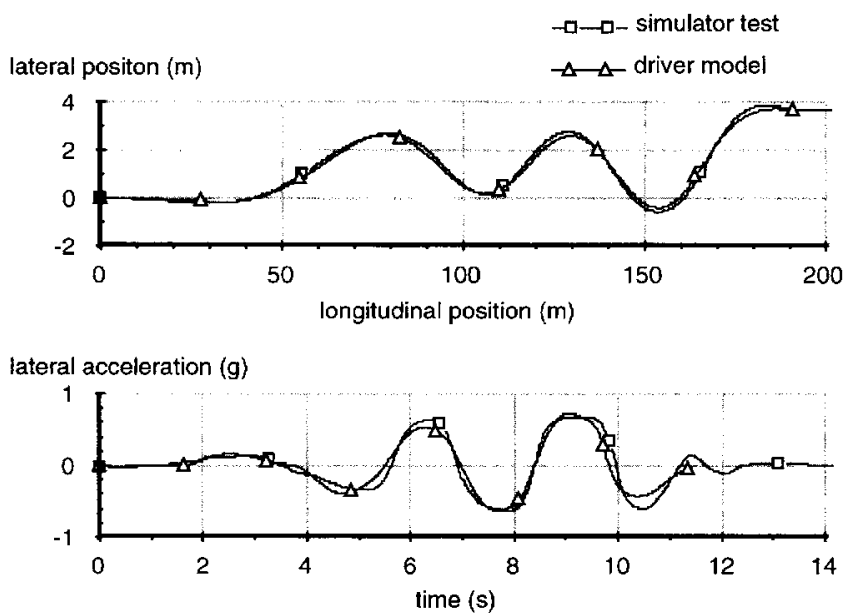

driver front wheel steer angle (deg)

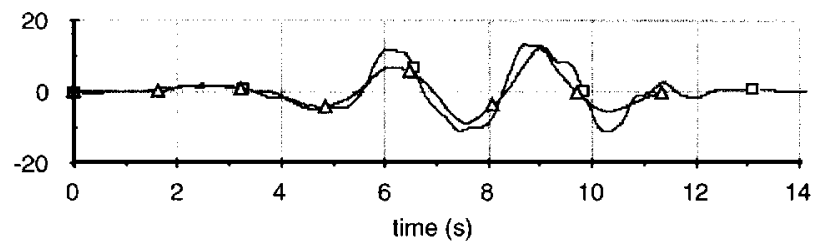

yaw rate $(\mathrm{deg} / \mathrm{s})$

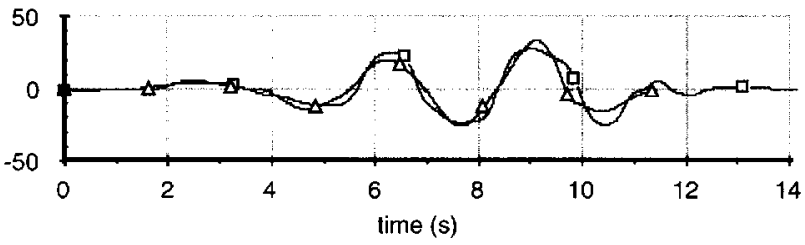

Fig. 7. Example moving-base simulator test vs. model result - slalom maneuver: $17 \mathrm{~m} / \mathrm{s}$.

conditions within a moving-base driving simulator, Figure 7 shows a very representative set of example time history comparisons.

This particular measurement corresponds to a 67-year-old male driver operating a light truck vehicle at $17 \mathrm{~m} / \mathrm{s}$ as part of tests [159] conducted in the simulator environment. The maneuver corresponds to a slalom-like course with indicated peak lateral acceleration levels of about $0.7 \mathrm{~g}$ 's. This result is fairly typical of the type of matching achieved between the cited nonlinear driver model predictions and a set of simulator experiments utilizing a group of twelve drivers ranging in skill level from expert to novice. The test maneuvers included double lane changes, a slalom course, and lane changes along a circular curve. 


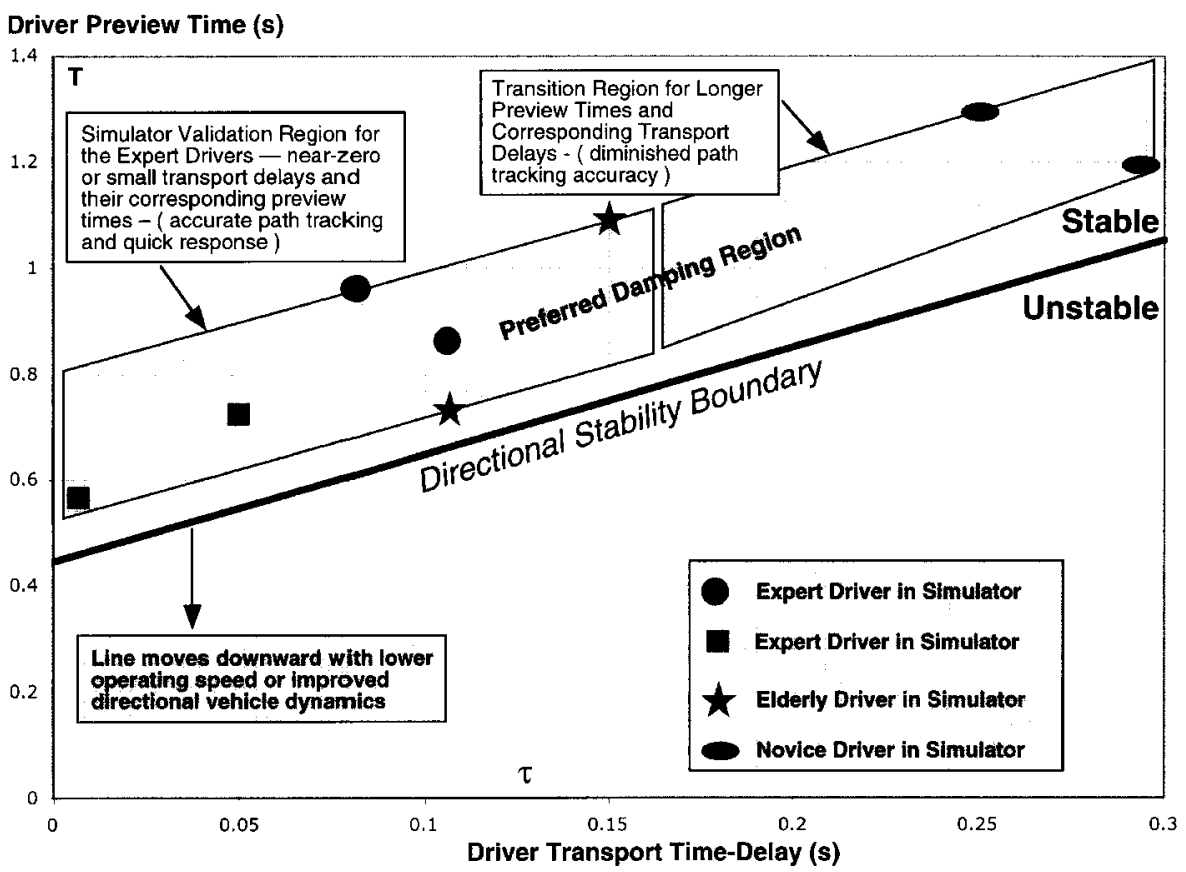

Fig. 8. Example GM/UMTRI driver model parameter regions identified from limit maneuver simulator tests.

One of the basic observations from these tests was that drivers operating near their limit performance appear to adjust their preview time utilization and transport time delay characteristics in a coordinated manner so as to generate a level of preferred damping for the closed-loop system just shy of the stability limit. This can best be described by the diagram seen in Figure 8 where the validated preview time and transport time delay parameters of the nonlinear model [159] are plotted against each other. The indicated parameter regions correspond to several different drivers from the aforementioned simulator tests and their respective model parameters identified within that validation study. As seen in Figure 8, a linear-like scattering of T (preview time) and $\tau$ (transport delay) pairs occurs within a region of "preferred damping" that is distributed upward and to the right on this diagram. Also seen on this plot is the directional stability boundary that lies below the preferred damping region. The stability line represents the minimal driver preview time required to provide a neutrally stable driver-vehicle system for a given level of driver transport time delay. As indicated by these results, drivers of varying skill appear to distribute their primary control behavior within this preferred damping region. The more expert and 
experienced drivers are able to utilize shorter preview times and generate near-zero transport delay characteristics. Less experienced drivers are not as able to minimize their transport delay properties and therefore require somewhat greater preview times in order to maintain directional stability under similar conditions.

In fact, there appears to be a tradeoff between driver preview time utilization and driver transport delay suggested by this relationship that is also related to closed-loop system maneuverability. The greatest maneuverability for the driver-vehicle system coincides with short preview times. Longer preview times (and their longer accompanying look-ahead distances) produce greater filtering or attenuation of the previewed path seen by the driver, particularly as the wavelength of the required input path is shortened - as during sharp turning. Thus, a natural tendency to utilize shorter preview or "look-ahead" times occurs with drivers under these more maneuverdemanding conditions. The relationship between preview time and transport delay seen in Figure 8 suggests that as drivers shorten their preview time to match the required path tracking or maneuverability requirements imposed by the upcoming road geometry, corresponding reductions in their transport delay properties must accordingly accompany such preview time reductions in order to maintain a similar level of system directional stability. Those drivers less able to reduce their transport delay characteristics must settle for an accompanying level of increased preview utilization that preserves closed-loop directional stability, but at the expense of reduced path maneuverability. In fact, the same simulator experiments [159] with expert and novice drivers reflected this basic trend. Namely, novice drivers were more likely to drive slower and to sacrifice path accuracy in order to retain directional stability near the limit, versus more experienced drivers that were better able to successfully maneuver the required courses at higher speeds and were more likely to exhibit directional instability as a form of failure.

While this information is especially useful for better understanding driver steering control activity near the limit and helps in modeling such behavior, it only represents a portion of the overall picture, especially when considering the potential range of different driver skills and operating conditions.

\subsection{Related Lateral Control Studies}

Figure 9 shows an expanded version of Figure 8 that covers a greater range of both preview time and transport delay properties. A number of regions labeled as A [159], B [115], C [108], D [108], and E [108, 113] also appear in Figure 9 and correspond to prior experimental and model validation studies that identified similar combinations of driver preview time and transport delay values. The indicated studies ranged from straight-line regulation steering $(\mathrm{E})$, to intermediate obstacle avoidance or slalom maneuvers (B, C, D), to limit maneuvering in slalom and double lane-changes (A). All drivers in these steering maneuvers were fully engaged and attentive to the 


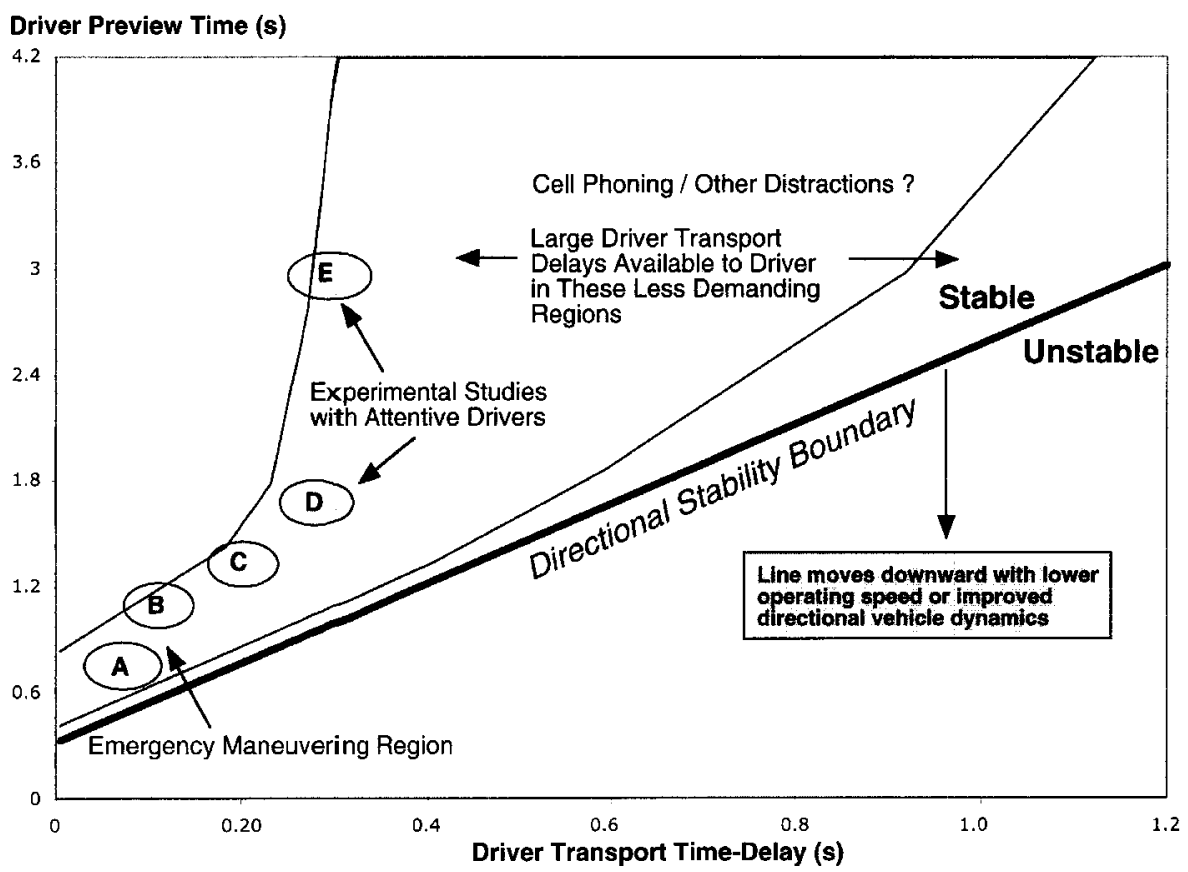

Fig. 9. Broader perspective of the relationship between driver preview utilization and driver delay properties during lateral control tasks.

steering tasks at hand. The combined information from these different studies regarding driver preview utilization and driver delay properties supports the trends observed in Figure 8 for limit maneuvering and the concept of a preferred level of closed-loop directional damping. That is, as driver preview time is adjusted to accommodate upcoming path or obstacle avoidance requirements for different maneuvers, driver transport delay properties are adjusted accordingly to maintain a minimal level of stability for the most demanding maneuvers. However, as the lateral maneuvering requirements decrease - as reflected by correspondingly longer preview time utilization - associated stability margins increase as indicated by the lengthier transport delays available to drivers in these less demanding driving scenarios.

For example, the stability line of Figure 9 is specific to the region A data, but is still illustrative of the type of stability lines applicable to the other cited data. That is, as longer preview times become available to the driver for path control because of longer wavelength characteristics of the required path input, correspondingly longer transport delays can be elected by the driver and still maintain directional and path stability of the vehicle. It is interesting to observe on this diagram that as preview time usages do increase, especially during straight-line driving scenarios, so also do the 
driver transport time stability margins, particularly with respect to the indicated measurements of attentive drivers (region E in Fig. 9) engaged in straight-line steering regulations tasks. That is, drivers can elect to significantly increase their time delays under these more benign conditions and still technically maintain directional control of the vehicle. It is not surprising then that cell phone usage and other driver distractive activities that effectively produce longer driver transport delays - by promoting intermittent driver control behavior and reduced attentiveness - are commonly observed to populate these less demanding driver control regions. The associated "sample-control-hold" steering behavior of drivers engaging in such activities essentially introduces an effective transport delay approximately equal to one-half of the sample time. (Similar longitudinal control behavior of drivers during long-range headway control engagements would elicit the same delay effect.)

\subsection{Potential Relationship to Longitudinal Control Modeling}

The preview time versus transport delay relationship of Figure 9 may also have application to the realm of longitudinal control. For example, the driver preview time and transport delay axes of Figure 9 that are seen as applicable to lateral maneuvering scenarios, may also apply to longitudinal headway control through use of the more conceptual diagram seen in Figure 10. The basic idea of Figure 10 is to portray driver preview or anticipatory behavior of the driver on one axis and to relate it to driver delay properties on the other axis - in the most general sense. That is, the driver preview or anticipatory time may be associated either with lateral (as above) or longitudinal control behavior (as in [36, 139, 144, 146, 151]). The driver preview or anticipatory behavior element is directly adjustable by the driver based on operating conditions and maneuver requirements. The delay properties of the abscissa axis are determined either by physical limitations of the driver (smaller delay values) during demanding braking/acceleration maneuvers, or are elected by the driver (larger delay values) during times or maneuvers of minimal control activity. For example, longitudinal headway control involving lengthy headway (preview) times, or driver straight-line path regulation tasks involving intermittent distractions, would appear on such a diagram in the vicinity of the upper right corner. Limit maneuvering for both lateral (as above) or hard braking scenarios $[36,144]$ would lie more to the lower left vicinity on such a diagram. More routine intermediate lateral and longitudinal maneuvering scenarios would lie in the indicated mid-range area.

A longitudinal stability boundary line is also depicted on the conceptual diagram of Figure 10, similar to that seen in for the lateral maneuvering scenarios of Figure 9. As loosely depicted here, a similar qualitative stability relationship may exist for both the longitudinal as well as the lateral driver control problem - one that associates longer driver preview or anticipatory times with greater leeway or allowances for driver delay properties, and vice versa. Furthermore, an instinctive behavior involving 


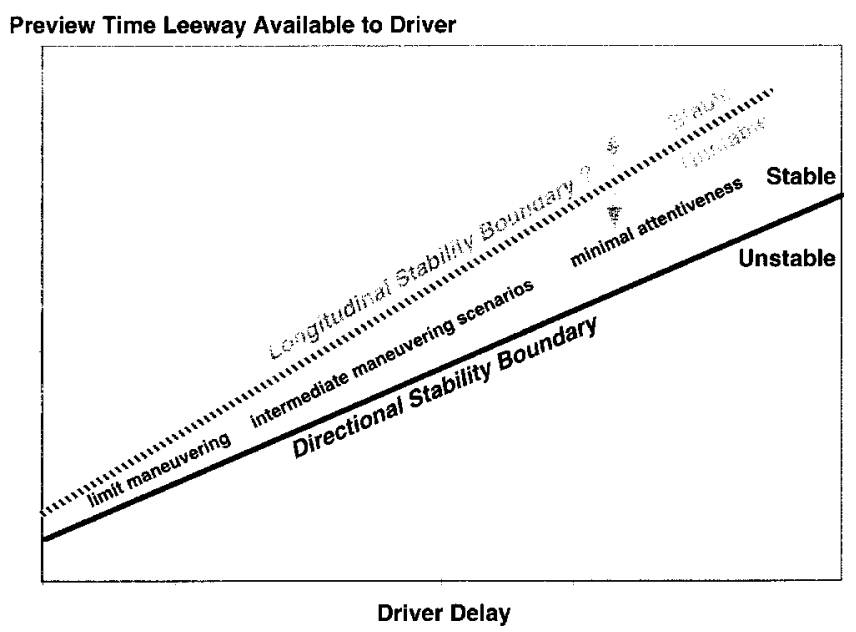

Fig. 10. Conceptual diagram describing potential relationship between available driver preview and driver delay properties for both lateral and longitudinal control tasks.

both of these qualities may be involved such that a tradeoff between maneuverability and stability is successfully accommodated by the human driver.

Future modeling efforts aimed at combined lateral and longitudinal control behavior of drivers will likely clarify some of these possible mirrored relationships. Indeed, some form of synchronized or harmonious preview control behavior that accounts simultaneously for lateral as well as longitudinal path or obstacle avoidance control strategies would seem natural and appealing, if feasible. This would then permit a melding of these two separate (as currently treated) control behaviors, into one integrated control structure that accounts jointly for the lateral and longitudinal control behavior exhibited by the human driver.

\section{CONCLUSIONS}

To be a human driver means exhibiting traits that include certain physical limitations as well as attributes. It is essential then that models of driver control behavior (applicable to conventional ground vehicles) include first and foremost:

- provision for human transport time delay properties;

- driver preview utilization (variable) for both lateral and longitudinal control;

- adaptive driver capabilities that reflect knowledge or understanding of the controlled plant (vehicle) dynamics and that recognize changes in operating conditions and/or plant dynamics; 
- use of an internal vehicle model (or its equivalent) so as to permit projection or estimation of future vehicle states;

- dynamic response characteristics that exhibit combined driver-vehicle "cross-over model" behavior within the linear operating regime near the cross-over frequency;

- linear dynamic response characteristics at low frequencies that exhibit increased gains approaching $-60 \mathrm{db} /$ decade and corresponding phase margins of -270 degrees approaching DC.

A set of important but more secondary traits include:

- provision for modification of path inputs or path planning by the driver (corner cutting behavior, etc.);

- inclusion of driver sensory input processing elements;

- inclusion of neuromuscular and related output channel properties;

- provisions for driver skill-related characteristics that can be represented by either coordinated sets of driver model parameters, or certain ad hoc features that are applicable to specific problems (e.g., situational awareness delays, etc.).

Accurate and representative modeling of these human characteristics means including at least the primary set of noted traits. More refined and potentially accurate driver models would include traits from the secondary set as well, depending upon the applications.

The most direct method available to drivers for altering the control characteristics of the closed-loop driver-vehicle system is through adjustment of their preview and time delay properties. This is evident from numerous analyses and computer modeling studies of driver-vehicle response data - across all ranges of the maneuvering spectrum - that illustrate the powerful leverage that these two driver characteristics have over the behavior of the closed-loop system.

Much remains to further our understanding of the complex and highly individualized control behavior of the human driver. Nevertheless, significant progress has been achieved in recent decades, particularly in computer-based descriptions and representations of specific examples of human driver control behavior.

Example areas of further advanced work include: (1) driver skill-related issues and discriminatory techniques for recognizing/representing driver skill in analyses and computer models, (2) addressing developing trends in smart vehicles and their potential interactions with human drivers in control of the vehicle, (3) better understanding and characterization of novice and less experienced driver control behavior, (4) improvements in understanding how drivers "internalize" their view of the external world/controlled vehicle and associated methods for modeling those human conceptualizations, and (5) advancement of human driver control modeling so that the lateral and longitudinal control behaviors of the human driver can be represented in a more unified and natural manner, rather than as a collection of 
scattered models that represent only specific instances of these types of driver control behavior. To support and validate these advancements, suitable measurements of human-vehicle interactions under a wide variety of operating conditions will be required.

\section{REFERENCES}

1. Bekey, G.A.: The Human Operator as a Sampled-Data System, IRE Trans. Human Factors Electr. HFE-3 (September) (1962).

2. Elkind, J.I.: A Survey of the Development of Models for the Human Controller. Progr. Astronaut. Aeronaut. (1964), pp. 623-643.

3. Jex, H. and Cromwell, C.: Theoretical and Experimental Investigation of New Longitudinal Handling Quality Parameters, ASD-TR-61-26, 1961.

4. Li, Y.T., Young, L.R. and Meiry, J.L.: Adaptive Functions of Man in Vehicle Control Systems. In: Proceedings of the International Federation of Automatic Control Symposium, Paddington, England, 1965.

5. Mcruer, D. and Jex, H.: A Review of Quasi-Linear Pilot Models. Trans. Human Factors Electron. 8 (1967).

6. McRuer, D.T., Hofmann, L.G., Jex, H.R., Moore, G.P., Phatak, A.V., Weir, D.H. and Wolkovitch, J.: New Approaches to Human-Pilot/Vehicle Dynamic Analysis. Technical Report AFFDL-TR-67-150. WPAFB, 1968.

7. Miller, D.C.a.E., J.I.: The Adaptive Response of the Human Controller to Sudden Changes in Controlled Process Dynamics. IEEE Trans. Human Factors Electron. HFE 8 (3) (1967).

8. Ornstein, G.N.: The Automatic Analog Determination of Human Transfer Function Coefficients. Med. Electron. Bio. Eng. 1 (3) (1963).

9. Pew, R., Duffenbach, J. and Fensch, I.: Sine Wave Tracking Revisited. In: Proceedings of the IEEE Transactions on Human Factors in Electronics, HFE-8, 1967.

10. Phatak, A. and Weir, D.: On the Dynamic Response of the Human Operator to Transient Inputs. NASA Spec. Publ. 192 (1968), pp. 21-23.

11. Phatak, A. and Bekey, G.: Model of the Adaptive Behavior of the Human Operator in Response to a Sudden Change in the Control Situation. IEEE Trans. Man Machine Syst. 10 (3) (1969), pp. 72-80.

12. Wallach, H.: Performance of a Pursuit Tracking Task with Different Time Delay Inserted Between the Control Mechanism and the Display Cursor. Tech. Mem. 12-61, 1961.

13. Weir, D. and Phatak, A.V.: Model of Human Response to Step Transitions in Controlled Element Dynamics. Technical Report NASA CR-671, 1968.

14. Young, L.R. and Stark, L.: Biological Control Systems - a Critical Review and Evaluation. NASA Contractor Report, NASA CR-190, 1965.

15. Millsum, J.H.: Biological Control Systems Analysis. McGraw-Hill, New York, 1966.

16. Crossman, E. and Szostak, H.: Man-Machine Model for Car Steering. In: Proceedings of the Fourth Annual NASA-University Conference on Manual Control, Ann Arbor, MI, 1968.

17. Kondo, M. and Ajimine, A.: Driver's Sight Point and Dynamics of the Driver-Vehicle System Related to It. In: Proceedings of the SAE Automotive Engineering Congress, Detroit, MI, 1968.

18. Weir, D. and McRuer, D.: Model for Steering Control of Motor Vehicles. In: Proceedings of the Fourth Annual NASA-University Conference on Manual Control, Ann Arbor, MI, 1968.

19. Wierwille, W.W., Gagne, G.A. and Knight, J.R.: An Experimental Study of Human Operator Models and Closed-Loop Analysis Methods for High-Speed Automobile Driving. In: Proceedings of the IEEE Transactions on Human Factors in Electronics, HFE-8 (September), 1967. 
20. Yoshimoto, K., Simulation of Man-Automobile Systems by the Driver's Steering Model with Predictability. Bull. Jpn. Soc. Mech. Eng. 12 (51) (1969), pp. 495-500.

21. McLean, J.R. and Hoffman, E.R.: Analysis of Drivers' Control Movements. Human Factors 13 (1971), pp. 407-418.

22. McRuer, D.T. and Klein, R.: Effects of Automobile Steering Characteristics on Driver Vehicle System Dynamics in Regulation Tasks. In: Proceedings of the 11th Annual Conference on Manual Control, 1975.

23. McRuer, D.T. and Klein, R.: Comparison of Human Driver Dynamics in Simulators with Complex and Simple Visual Displays and in an Automobile on the Road. In: Proceedings of the 11th Annual Conference on Manual Control, 1975.

24. Mortimer, R.G. and Jorgeson, C.M.: Eye Fixations of Drivers as Affected by Highway and Traffic Characteristics and Moderate Doses of Alcohol. In: Proceedings of the 16th Annual Meeting, Human Factors Society, 1972.

25. Rashevsky, N.: Some Remarks on the Mathematical Aspects of Automobile Driving. Bull. Math. Biophys. 21 (1959), pp. 299-308.

26. Repa, B. and Wierwille, W.: Driver Performance in Controlling a Driving Simulator with Varying Vehicle Response Characteristics. In: SAE Proceedings, 1976.

27. Segel, L. and Mortimer, R.G.: Driver Braking Performance as a Function of Pedal-Force and PedalDisplacement Levels. In: Proceedings of the SAE Transactions, 1970.

28. Sweatman, P. and Joubert, P.: Automobile Directional Characteristics and Driver Steering Performance. Vehicle Syst. Dyn. 5 (3) (1976).

29. Weir, D. and McRuer, D.: Dynamics of Driver Vehicle Steering Control. Automatica 6 (1) (1970).

30. Weir, D. and Wojcik, C.: Simulator Studies of the Driver's Dynamic Response in Steering Control Tasks. Highway Res. Record 364 (1971), pp. 1-15.

31. Weir, D. and McRuer, D.: Measurement and Interpretation of Driver/Vehicle System Dynamic Response. Human Factors 15 (1973), pp. 367-378.

32. Rashevsky, N.: Automobile Driving as Psychophysical Discrimination. Bull. Math. Biophys. 24 (1962), pp. 319-325.

33. Rashevsky, N.: Neglected Factors in Highway Safety. University of Michigan Mental Health Research Institute, Grant GM-12032-01, 1966.

34. Gordon, D.A.: Perceptual Bases of Vehicular Guidance. Public Roads 34 (3) (1966).

35. McLane, R.C. and Wierwille, W.W.: Influence of Motion and Audio Cues on Driver Performance in an Automobile Simulator. Human Factors 17 (5) (1975).

36. McLean, D., Newcomb, T.P. and Spurr, R.T.: Simulation of Driver Behavior During Braking. In: Proceedings of the International Mechanical Engineers Conference on Braking of Road Vehicles, 1976.

37. McRuer, D.T., Weir, D.H., Jex, H.R., Magdaleno, R.E. and Allen, R.W.: Measurement of DriverVehicle Multiloop Response Properties with a Single Disturbance Input. IEEE Transactions on Systems, Man, and Cybernetics (1975), pp. 490-497.

38. Good, M.: Sensitivity of Driver-Vehicle Performance to Vehicle Characteristics Revealed in OpenLoop Tests. Vehicle Syst. Dyn. 6 (4) (1977), pp. 245-277.

39. Reid, L.D.: Survey of Recent Driver Steering Behavior Models Suited to Accident Studies. Accident Anal. Prevention 15 (1) (1983), pp. 23-40.

40. Guo, K. and Guan, H.: Modelling of Driver/Vehicle Directional Control System. Vehicle Syst. Dyn. 22 (3-4 May-July) (1993), pp. 141-184.

41. Peng, H.: Evaluation of Driver Assistance Systems - a Human Centered Approach. In: AVEC Proceedings, 2002.

42. Alexandridis, A., Repa, B. and Wierwille, W.: Influence of Vehicle Aerodynamic and Control Response Characteristics on Driver-Vehicle Performance, SAE, 1979. 
43. Apel, A. and Mitschke, M.: Adjusting Vehicle Characteristics by Means of Driver Models. Int. J. Vehicle Des. 18 (6) (1997), pp. 583-596.

44. Donges, E.: Two-Level Model of Driver Steering Behavior. Human Factors 20 (1978), pp. 691-707.

45. Irmscher, M., Jurgensohn, T. and Willumeit, H.-P.: Driver Models in Vehicle Development. Vehicle Syst. Dyn. 33 (Suppl.) (2000), pp. 83-93.

46. MacAdam, C.C., Sayers, M.W., Pointer, J.P. and Gleason, M.: Crosswind Sensitivity of Passenger Cars and the Influence of Chassis and Aerodynamic Properties on Driver Preferences. Vehicle Syst. Dyn. 19 (4), 1990.

47. Modjtahedzadeh, A. and Hess, R.A.: Model of Driver Steering Control Behavior for Use in Assessing Vehicle Handling Qualities. J. Dyn. Syst. Measur. Contr. Trans. ASME 115 (1993), pp. 456-464.

48. Plochl, M. and Lugner, P.: 3-Level Driver Model and Its Application to Driving Simulations. Vehicle Syst. Dyn. 33 (Suppl.) (2000), pp. 71-82.

49. Repa, B.S., Alexandridis, A.A., Howell, L.J. and Wierwille, W.W.: Influence of Vehicle Control Dynamics on Driver-Vehicle Performance. In: Proceedings of the IAVSD Symposium, 1977.

50. Schuller, J., Schaefer, F., Neukum, A. and Krueger, H.-P.: Driver Model as Development Tool for Vehicle Handling Design. Vehicle Syst. Dyn. 33 (Suppl.) (2000), pp. 110-121.

51. Sharp, R., Casanova, D. and Symonds, P.: A Mathematical Model for Driver Steering Control, with Design, Tuning and Performance Results. Vehicle Syst. Dyn. 33 (5) (2000), pp. 289-326.

52. Boff, Kaufman and Thomas (eds.): Handbook of Perception and Human Performance - Sensory Process and Perception, Vol. 1. Wiley-Interscience, New York, 1986.

53. Boff, Kaufman and Thomas (eds.): Handbook of Perception and Human Performance - Cognitive Processes and Performance, Vol. 2. Wiley-Interscience, New York, 1986.

54. Henderson, R.L.E.: Driver Performance Data Book. Final Report DOT HS 807 126, NHTSA, 1987.

55. Jagacinski, R.J. and Flach, J.M.: Control Theory for Humans. Lawrence Erlbaum Associates, Mahwah, NJ, 2003.

56. Johannsen, G.: Man-Machine Systems - Introduction and Background. In: Proceedings of the IFAC Man-Machine Systems, Baden-Baden, Federal Republic of Germany, 1982.

57. Pew, R.W.a.B., S.: Perspectives on Human Performance Modelling. In: Proceedings of the IFAC ManMachine Systems, Baden-Baden, Federal Republic of Germany, 1982.

58. Sheridan, T.B.: Forty-Five Years of Man-Machine Systems: History and Trends. In: Proceedings of the IFAC Man-Machine Systems, Varese, Italy, 1985.

59. Woodworth, R.: Experimental Psychology. Henry Holt, New York, 1938.

60. Woodworth, R. and Shlosberg, H.: Experimental Psychology, Rev Ed. Holt, Rinehart, and Winston, New York, 1954.

61. MacAdam, C.C.: Vehicle Induced Feedback Cues and Their Relationship to Driver Performance and Safety, UMTRI-95-41, 1995.

62. Warrick, F.: Effect of Transmission-Type Control Lags on Tracking Accuracy, ASAF TR 5916, 1949.

63. Teichner, W.: Recent Studies of Simple Reaction Time. Psychol. Bull. 51 (1954).

64. Teichner, W. and Krebs, M.: Laws of Simple Visual Reaction Time. Psychol. Rev. 79 (1972).

65. Miller, R.: Plans and the Structure of Target Acquisition Behavior. In: Proceedings of the 25th Human Factors Meeting, 1981.

66. Breimeyer, B.: A Relationship between Detection of Size, Rate, Orientation, and Direction of Motion in the Human Visual System. Vision Res. 13 (1973).

67. Lappin, J.: On the Relation Between Time and Space in the Visual Discrimination of Velocity. J. Exp. Psychol. 1 (1975).

68. Pantle, A. and Sekular, R.: Velocity Sensitive Elements in Human Vision. Vis. Res. 8 (1968).

69. Sekular, R.: Handbook of Perception. Academic, New York, 1979.

70. Levison, W.: The Optimal Control Model for the Human Operator: Theory, Validation, and Applications. In: Proceedings of the Workshop on Flight Testing to Identify Pilot Workload, 1982. 
71. McRuer, D.T.: Human Dynamics in Man-Machine Systems. Automatica 16 (1980), pp. 237-253.

72. Gottsdanker, R.: Prediction-Motion with and without Vision. J. Psychol. 65 (1952).

73. Roscoe, S.: Aviation Psychology. Iowa State University Press, Ames, IA, 1980.

74. Bruel, H.: Some Effects of Field of View and Target Size on Lateral Tracking at Hover. In: Proceedings of the 17th Annual Conference on Manual Control, 1981.

75. Moriarty, T., Junker, A. and Price, D.: Roll Axis Tracking Resulting from Peripheral Vision Motor Cues. In: Proceedings of the 12th Annual Conference on Manual Control, 1976.

76. Swartzengruber, L.: Two Linear Rate-Field Displays. Human Factors 13 (1971).

77. Reid, D. and Drewell, N.: A Pilot Model for Tracking with Preview. In: Proceedings of the Eighth Annual Conference on Manual Control, 1972.

78. Hosman, R. and Stassen, H.: Pilot's Perception in the Control of Aircraft Motions. Contr. Eng. Pract. 7 (11) (1999), pp. 1421-1428.

79. Hosman, R.J.A.W.a.v.d.V., J. C.: Laboratory and Moving-Base Simulator Experiments on Speed and Accuracy of Visual and Whole-Body Motion Perception. In: Proceedings of the IFAC Man-Machine Systems, Varese, Italy, 1985.

80. Junker, A.M. and Levison, W.H.: Application of Control Theory to the Investigation of Roll Motion Effects on Pilot Control Behavior. In: Proc. IEEE Conf. Decis. Control Incl. Symp. Adapt Processes, New Orleans, 1977.

81. Levison, W. and Junker, A.: A Model for the Pilot's Use of Motion Cues in Roll-Axis Tracking Tasks, NASA CR-1746, 1977.

82. Levison, W., Lancraft, R. and Junker, A.: Effects of Simulator Delays on Performance and Learning in a Roll-Axis Tracking Task, AFFDL-TR-79-3134, 1979.

83. Repa, B., Leucht, P. and Wierville, W.: Effect of Simulator Motion on Driver Performance. In: SAE Proceedings, 1982.

84. Wierwille, W.W., Casali, J. and Repa, B.: Driver Steering Reaction Time to Abrupt-Onset Crosswinds, as Measured in a Moving-Base Driving Simulator. Human Factors 25 (1983), pp. 103-116.

85. Levison, W. and Zacharias, G.: An Optimal Control Model for the Joint Use of Visual and Motion Cues in Continuous Tracking Tasks: Theory and Experiments. J. Cybernet. Inform. Sci. 3 (1980).

86. Blaauw, G.J., Godthelp, J. and Milgram, P.: Optimal control model applications and field measurements with respect to car driving. Technical Report, IZF198318, 1983.

87. Vinge, E., Operator for Aural Compensatory Tracking. In: Proceedings of the Seventh Annual Conference on Manual Control, 1971.

88. Vinge, E. and Pitkin, E.: Human Operator Dynamics for Aural Compensatory Tracking. In: Proceedings of the IEEE Transactions on Systems, Man, and Cybernetics, SMC-2, 1972.

89. Schumann, J., Godthelp, H., Farber, B., Wontorra, H., Gale, A., Brown, I., Haslegrave, C., Kruysse, H. and Taylor, S.: Breaking up Open-Loop Steering Control Actions: The Steering Wheel as an Active Control Device. In: Proceedings of the Vision in Vehicles, Vol. IV, Leiden, Netherlands, 1993.

90. Murray, C.: Torque Sensor Steering. Popul. Sci. 12 (1994).

91. Peacock, B. and Karwowski, W.: Automotive Ergonomics. Taylor \& Francis, London, 1993.

92. Riemersma, J.: Visual Cues in Straight Road Driving. TNO Institute for Perception Report, 1987.

93. Schieber, F.: Recent Developments in Vision, Aging, and Driving: 1988-1994, Report UMTRI-94-26, 1994.

94. Poulton, E.: Tracking Skill and Manual Control. Academic, London, 1974.

95. Wickens, C. and Derrick, W.: The Processing Demands of Second-Order Manual Control, EPL-81-1/ ONR-81-1, 1981.

96. Costello, R.: The Surge Model of the Well Trained Human Operator in Simple Manual Control. IEEE Trans. Man-Machine Syst. MMS-9 (1968).

97. Hess, R.: A Rationale for Human Operator Pulsive Control Behavior. J. Guidance Contr. 2 (1979). 
98. Young, L.R. and Meiry, J.: Bang-Bang Aspects of Manual Control in Higher Order Systems. In: Proceedings of the IEEE Transactions on Automatic Control, Vol. 6, 1965.

99. Sheridan, T.B.: Control Models of Creatures Which Look Ahead. In: Proceedings of the Fifth National Symposium on Human Factors in Electronics, 1964.

100. Sheridan, T.B.: Three Models of Preview Control. In: Proceedings of IEEE Transactions on Human Factors in Electronics. HFE-7 (June), 1966.

101. Yoshimoto, K. and Akashi, H.: A Self-Paced Preview Tracking Control Model of an Automobile Driver. In: Proceedings of the Eighth Triennial World Congress of the International Federation of Automatic Control, Kyoto, Japan, 1982.

102. Yoshimoto, K., Katoh, M. and Inoue, K.: A Vision-Based Speed Control Algorithm for Autonomous Driving. In: Proceedings of AVEC 2000 Fifth International Symposium on Advanced Vehicle Control, Ann Arbor, MI, 2000.

103. Baron, S.: A Model for Human Control and Monitoring Based on Modern Control Theory. J. Cybern. Inform. Sci. 1 (1976).

104. Kleinman, D., Baron, S. and Levison, W.: Control Theoretic Approach to Manned Vehicle Systems Analysis. In: Proceedings of the Automatic Control Conference, 1971.

105. Kleinman, D.L., Baron, S. and Levison, W.H.: An Optimal Control Model of Human Response, Part I: Theory and Validation. Automatica 6 (1970), pp. 357-369.

106. Tomizuka, M.: The Optimal Finite Preview Problem and Its Application to Man-Machine Systems. PhD Dissertation, MIT, 1973.

107. MacAdam, C.C.: An Optimal Preview Control for Linear Systems. J. Dyn. Syst. Measur. Contr. 102 (September) (1980), pp. 188-190.

108. MacAdam, C.C.: Application of an Optimal Preview Control for Simulation of Closed-Loop Automobile Driving. In: Proceedings of the IEEE Transactions on Systems, Man, and Cybernetics, SMC-11, June 1981, pp. 393-399.

109. Levison, W.: A Simulation Model for the Driver's Use of in-Vehicle Information Systems. Transportation Res. Record 1403 (1993), pp. 7-13.

110. Levison, W. and Cramer, N.L.: Description of the Integrated Driver Model. Final Report, BBN7840, 1995.

111. Levison, W.: Interactive Highway Safety Design Model: Issues Related to Driver Modeling. Transportation Res. Record (1998), pp. 20-27.

112. McRuer, D.T., Allen, R.W. and Klein, R.H.: New Results in Driver Steering Control Models. Human Factors 19 (4) (1977), pp. 381-397.

113. Weir, D., DiMarco, R.J. and McRuer, D.T.: Evaluation and Correlation of Driver/Vehicle Data, Vol Ii, in Final Technical Report, NHTSA, DOT-HS-803-246, 1977.

114. MacAdam, C.C.: Frequency Domain Methods for Analyzing the Closed-Loop Directional Stability and Maneuverability of Driver/Vehicle Systems. In: Proceedings of the Conference on Modern Vehicle Design Analysis, London, U.K., 1983.

115. MacAdam, C.C.: Development of Driver/Vehicle Steering Interaction Models for Dynamic Analysis. Final Technical Report, UMTRI-88-53. U.S. Army TACOM Contract DAAE07-85-C-R069, 1988.

116. Miller, T.W., Sutton, R.S. and Werbos, P.J. (eds.): Neural Networks for Control. MIT Press, Cambridge, 1995.

117. Guo, K., Pan, F., Cheng, Y. and Ding, H..: Driver Model Based on the Preview Optimal Artificial Neural Network. In: AVEC Proceedings, 2002.

118. Kageyama, I., Arai, A. and Nomura, T.: Analysis of Driver's Control Algorithm Using Neural Network Modeling. Vehicle Syst. Dyn. 33 (Suppl.) (2000), pp. 122-130.

119. Kehtarnavaz, N. and Sohn, W.: Steering Control of Autonomous Vehicles by Neural Networks. In: Proceedings of the 1991 American Control Conference, 1991. 
120. Kornhauser, A.L.: Neural Network Approaches for Lateral Control of Autonomous Highway Vehicles. In: Conference Proceedings of Vehicle Navigation \& Information Systems, 1991.

121. Kraiss, K.F. and Kuttelwesch, H.: Teaching Neural Networks to Guide a Vehicle through an Obstacle Course by Emulating a Human Teacher. In: Proceedings of the 1990 International Joint Conference on Neural Networks - IJCNN 90, 1990.

122. Kraiss, K.F. and Kuttelwesch, H.: Identification and Application of Neural Operator Models in a Car Driving Situation. In: Proceedings of the Fifth IFAC/IFIP/IFORS/IEA Symposium on Analysis, Design and Evaluation of Man-Machine Systems 1992, 1993.

123. Lubin, J.M., Huber, E.C., Gilbert, S.A. and Kornhauser, A.L.: Analysis of a Neural Network Lateral Controller for an Autonomous Road Vehicle. In: Proceedings of the Future Transportation Technology Conference and Exposition, 1992.

124. MacAdam, C.C. and Johnson, G.E.: Application of Elementary Neural Networks and Preview Sensors for Representing Driver Steering Control Behaviour. Vehicle Syst. Dyn. 25 (1996), pp. 3-30.

125. MacAdam, C.C., Bareket, Z., Fancher, P. and Ervin, R.: Using Neural Networks to Identify Driving Style and Headway Control Behaviour of Drivers. In: Proceeding of the Dynamics of Vehicles on Roads and on Tracks, Budapest, Hungary, 1997.

126. MacAdam, C.C. and Bareket, Z.: Adaptive Neural Network Characterizations of Driver Longitudinal Control Behavior. In: Proceeedings of the International Symposium on Advanced Vehicle ControlAVEC 1998, 1998.

127. Kageyama, I. and Pacejka, H.B.: On a New Driver Model with Fuzzy Control. Vehicle Syst. Dyn. 20 (Suppl.) (1991), pp. 314-324.

128. Bernard, J., Gruening, J. and Hoffmeister, K.: Evaluation of Vehicle/Driver Performance Using Genetic Algorithms. In: SAE Conference Proceedings - Special Publication: Vehicle Dynamics and Simulation, pp. 73-85, Detroit, 1998.

129. Blank, M. and Margolis, D.L.: Minimizing the Path Radius of Curvature for Collision Avoidance. Vehicle Syst. Dyn. 33 (3) (2000), pp. 183-201.

130. Smiley, A., Reid, L. and Fraser, M.: Changes in Driver Steering Control with Learning. Human Factors 22 (4) (1980), pp. 401-415.

131. Casanova, D., Sharp, R. and Symonds, P.: On Minimum Time Optimisation of Formula One Cars: The Influence of Vehicle Mass. In: Proceedings of the AVEC 2000 Fifth International Symposium on Advanced Vehicle Control, Ann Arbor, MI, 2000.

132. Metz, D.: Near Time-Optimal Control of Racing Vehicles. Automatica 25 (6) (1989), pp. 841-857.

133. Apetaur, M. and Opicka, F.: Assessment of the Driver's Effort in Typical Driving Manoeuvres for Different Vehicle Configurations and Managements. Vehicle Syst. Dyn. 20 (Suppl) (1991), pp. 42-56.

134. Gordon, T., Dixon, P. and Best, M.: An Automated Driver Based on Convergent Vector Fields. In: Proceedings of AVEC 2000 Fifth International Symposium on Advanced Vehicle Control, Ann Arbor, MI, 2000.

135. Lugner, P. and Plochl, M.: Additional 4ws and Driver Interaction. Vehicle Syst. Dyn. 24 (8) (1995), pp. 639-658.

136. Patten, W., Wu, H. and Cai, W.: Perfect Parallel Parking Via Pontryagin's Principle. J. Dyn. Syst. Measur. Contr. Trans. ASME 116 (1994), pp. 723-728.

137. Allen, R.: Modelling Driver Steering Control Behavior. In: Proceedings of the IEEE Conference, Seattle, WA, USA. Sponsored by IEEE, 1982.

138. Amano, Y., Nagirl, S., Hada, M. and Doi, S.: Driver Behavior Model in Emergency Situations (on Basic Strucure of a Driver Model). Trans Jpn. Soc. Mech. Eng. 65 (633) (1999).

139. Fancher, P. and Bareket, Z.: Evolving Model for Studying Driver-Vehicle System Performance in Longitudinal Control of Headway. Transportation Res. Record 1631 (1998), pp. 13-19.

140. Godthelp, J.: Preview Control: Open and Closed Loop Automobile Steering at Curve Entrance. TNO Rept. IZF198433, 1984. 
141. Hess, R.A. and Modjtahedzadeh, A.: Preview Control Model of Driver Steering Behavior. In: Proceedings of the IEEE International Conference on Systems, Man and Cybernetics, 1989.

142. Kiencke, U., Majjad, R. and Kramer, S.: Modeling and Performance Analysis of a Hybrid Driver Model. Contr. Eng. Pract. (1999), pp. 985-991.

143. Nagai, M. and Mitschke, M.: Adaptive Behavior of Driver-Car Systems in Critical Situations: Analysis by Adaptive Model. JSAE Rev. (December) (1985), pp. 82-89.

144. Newcomb, T.P.: Driver Behavior During Braking. In: Proceedings of the SAE West Coast International Meeting, Seattle, 1981.

145. Prokop, G.: Modeling Human Vehicle Driving by Model Predictive Online Optimization. Vehicle Syst. Dyn. 35 (1) (2001), pp. 19-35.

146. Savkoor, A.R. and Ausejo, S., Analysis of Driver's Steering and Speed Control Strategies in Curve Negotiation. Vehicle Syst. Dyn. 33 (Suppl.) (2000), pp. 94-109.

147. Neusser, S., Nijhuis, J., Spaanenburg, L., Hoefflinger, B., Franke, U. and Fritz, H.: Neurocontrol for Lateral Vehicle Guidance. IEEE Micro. 13 (1) (1993), pp. 57-66.

148. Koike, Y. and Doya, K.: Multiple State Estimation Reinforcement Learning for Driving Model Driver Model of Automobile. In: Proceedings of the IEEE International Conference on Systems, Man and Cybernetics, Vol. 5, 1999, p. V-509.

149. Pomerleau, D.: Ralph: Rapidly Adapting Lateral Position Handler. In: Proceedings of the Intelligent Vehicles '95, Detroit, MI, USA. Sponsored by IEEE Ind. Electron. Soc, 1995.

150. Hedrick, K.: Longitudinal Vehicle Controller Design for I-V-H-S Systems. In: Proceedings of ACC, Boston, 1991.

151. Hisaoka, Y., Yamamoto, M. and Okada, A.: Closed-Loop Analysis of Vehicle Behavior During Braking in a Turn. JSAE Rev. 20 (4) (1999), pp. 537-542.

152. MacAdam, C.C.: Computer Model Predictions of the Directional Response and Stability of Driver Vehicle Systems During Anti-Skid Braking, In: Proceedings of the IMech E Conference on Antilock Braking Systems for Road Vehicles, London, U.K., 1985.

153. Rockwell, T. and Ernst, R.: Studies of Car Following. Ohio State Report No. 202B-5. 1965.

154. Rompe, K., Schindler, A. and Wallrich, M.: Comparison of the Braking Performance Achieved by Average Drivers in Vehicles with Standard and Anti Wheel Lock Brake Systems. In SAE International Congress and Exposition Proceedings, Detroit, MI, 1987.

155. Rompe, K., Wallrich, M. and Schindler, A.: Advantages of Anti Wheel Lock System (Abs) for the Average Driver in Difficult Driving Situations, 11-15 May 1987; Florence, Italy, Province Florence; Thermotech. Assoc. Tuscany; Univ. Florence, 1987.

156. Fambro, D.B., Koppa, R.J., Picha, D.L. and Fitzpatrick, K.: Driver Braking Performance in Stopping Sight Distance Situations. Transportation Res. Record 1701 (2000).

157. Gipps, P.G.: A Behavioral Car-Following Model for Computer Simulation. Transportation Res. B. 15 (1981), pp. 105-111.

158. Innocenti, M., Balluchi, A. and Balestrino, A.: New Results on Human Operator Modelling During Nonlinear Behavior in the Control Loop. In: Proceedings of the American Control Conference, Vol. 4, Evanston, IL, 1997.

159. MacAdam, C.C.: Development of a Driver Model for Near/At-Limit Vehicle Handling, UMTRI-200143. Sponsored by the General Motors Corporation, 2001. 